\title{
Novel Blue Organic Dye for Dye-Sensitized Solar Cells Achieving High Efficiency in Cobalt-Based Electrolytes and by Co-Sensitization
}

\author{
Yan Hao, ${ }^{\dagger}$ Yasemin Saygili, ${ }^{\dagger}$ Jiayan Cong, ${ }^{\S}$ Anna Eriksson, ${ }^{\dagger}$ Wenxing Yang, ${ }^{\dagger}$ Jinbao Zhang, ${ }^{\dagger}$ \\ Enrico Polanski, ${ }^{\ddagger}$ Kazuteru Nonomura, ${ }^{\dagger}$ Shaik Mohammed Zakeeruddin, ${ }^{\|, \perp}$ Michael Grätzel, ${ }^{\|}$ \\ Anders Hagfeldt, ${ }^{\dagger, \downarrow} \perp$ and Gerrit Boschloo ${ }^{*}, \dagger$
}

${ }^{\dagger}$ Department of Chemistry-Ångström Laboratory, Center of Molecular Devices, Uppsala University, SE-751 20 Uppsala, Sweden

${ }^{\ddagger}$ Laboratory of Photomolecular Science, Institute of Chemical Sciences and Engineering, École Polytechnique Fédérale de Lausanne, Chemin des Alambics, Station 6, CH-1015 Lausanne, Switzerland

${ }^{\S}$ Applied Physical Chemistry, School of Chemical Science and Engineering, Department of Chemistry, KTH Royal Institute of Technology, Teknikringen 30, SE-100 44 Stockholm, Sweden

"Laboratory of Photonics and Interfaces, Institute of Chemical Sciences and Engineering, École Polytechnique Fédérale de Lausanne, Chemin des Alambics, Station 6, CH-1015 Lausanne, Switzerland

${ }^{\perp}$ Center of Excellence for Advanced Materials Research (CEAMR), King Abdulaziz University, Jeddah 21589, Saudi Arabia

\section{Supporting Information}

ABSTRACT: Blue and green dyes as well as NIR-absorbing dyes have attracted great interest because of their excellent ability of absorbing the incident photons in the red and near-infrared range region. A novel blue $\mathrm{D}-\pi-\mathrm{A}$ dye (Dyenamo Blue), based on the diketopyrrolopyrrole (DPP)-core, has been designed and synthesized. Assembled with the cobalt bipyridine-based electrolytes, the device with Dyenamo Blue achieved a satisfying efficiency of $7.3 \%$ under one sun (AM1.5 G). The co-sensitization strategy was further applied on this blue organic dye together with a red $\mathrm{D}-\pi-\mathrm{A}$ dye (D35). The successful co-sensitization outperformed a panchromatic light absorption and improved the photocurrent density; this in addition to the open-circuit potential result in an efficiency of $8.7 \%$. The extended absorption of the sensitization and the slower recombination reaction between the blue dye and $\mathrm{TiO}_{2}$ surface inhibited by the additional red sensitizer could be the two main reasons for the higher performance. In conclusion, from the results, the highly efficient cobalt-based DSSCs could be

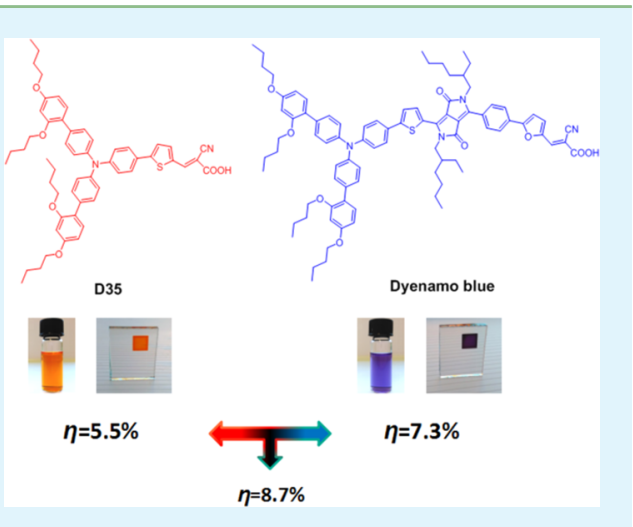
achieved with the co-sensitization between red and blue $\mathrm{D}-\pi-\mathrm{A}$ organic dyes with a proper design, which showed us the possibility of applying this strategy for future high-performance solar cells.

KEYWORDS: blue color, organic dyes, co-sensitization, cobalt electrolyte, dye-sensitized solar cells

\section{INTRODUCTION}

Dye-sensitized solar cells (DSSCs) have attracted great interest as a low-cost alternative to silicon solar cells, exhibiting moderate power conversion efficiencies. One crucial component of the DSSC devices is the monolayer of dye molecules, which is located at the interface of a mesoporous wide-bandgap semiconductor electrode and an electrolyte. ${ }^{1-5}$ This dye monolayer takes the function of light harvesting in the devices, and determines which part of the photons can be absorbed in the solar spectrum. So far, a large number of red dyes with strong absorption below $600 \mathrm{~nm}$ have been practiced in DSSCs successfully. However, this leaves a major part of the incident photons in the red and near-infrared (NIR) range unused. Therefore, the blue and green dyes as well as the NIRabsorbing dyes attracted particular interest. Additionally, the semitransparent solar cell devices with different colors are an extremely attractive technology for various applications including building integration. Although great efforts have been accomplished to design the blue or green dyes, few efficient sensitizers, compared to red dyes, have been developed. Squaraine-based sensitizers can reach a green or blue color, which absorbs the NIR region. However, the solar cell devices with this type of dyes always lead to low efficiencies. This is primarily due to the dye aggregation, poor electron injection, and low stability. ${ }^{6-12}$ Zinc phthalocyanines and perylene dyes are also favorable for their blue color and NIR absorption. However, both kinds of dyes did not show good performance until now. ${ }^{13-19}$ Recently, Holcombe et al. reported a series of diketopyrrolopyrrole (DPP)-based highperformance blue sensitizers for DSSCs, among which is the

Received: August 17, 2016

Accepted: October 28, 2016

Published: October 28, 2016 

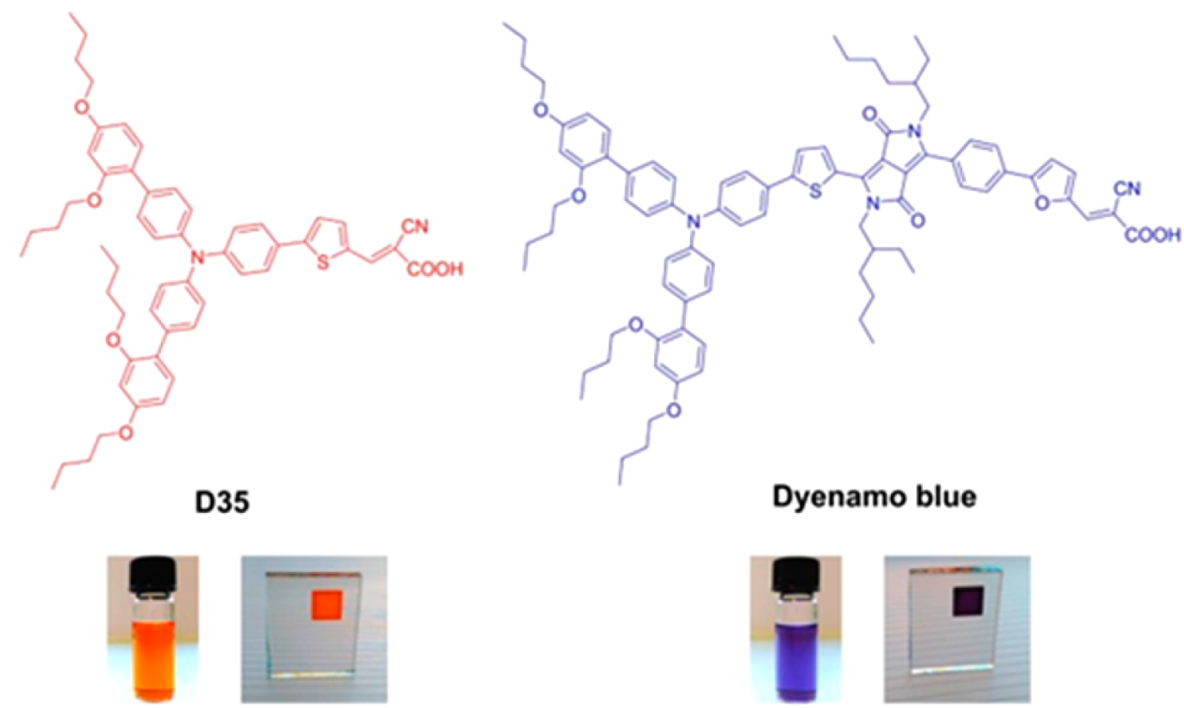

Figure 1. Chemical structures of the $\mathrm{D} 35$ and $\mathrm{DB}$ dyes and the dyes in solutions and on $\mathrm{TiO}_{2}$ films.

device with DPP17 sensitizer that achieved over 10\% PCE in combination with the $\left[\mathrm{Co}(\mathrm{bpy})_{3}\right]^{3+/ 2+}$ electrolyte at full sun $\left(\right.$ AM1.5 G)..$^{20}$

Co-sensitization of two or more dyes with complementary absorption regions is an effective approach to extend the absorption spectrum of the solar cell and enhance the photovoltaic properties of organic dyes based on DSSCs. ${ }^{21-33}$ Some successful co-sensitized DSSCs have been reported. In 2011, a porphyrin dye co-sensitized with an organic dye with cobalt-based electrolyte has been studied by Grätzel's group; an efficiency of $12.3 \%$ has been achieved. ${ }^{31}$ Recently, a record DSSC efficiency above $14 \%$ has been obtained with collaborative sensitization of silyl-anchor and carboxy-anchor dyes. $^{32}$ Most successful co-sensitization systems with cobalt electrolyte employed one metal-complex sensitizer (such as ruthenium or porphyrin dyes) or other dyes as main light absorber, and another dye took little function to slightly fill up the absorption gap. ${ }^{21,22,27-30,33}$ The co-sensitization of two pure organic dyes with very different absorption spectra has not been well-studied yet. Here, a pure organic co-sensitization system with very different color dyes, one red and one blue $\mathrm{D}-\pi-\mathrm{A}$ organic dyes, has been studied combined with cobaltbased electrolyte.

Herein, a new blue organic $\mathrm{D}-\pi-\mathrm{A}$ dye with broad absorption spectra, Dyenamo Blue (DB), has been designed and synthesized for the co-sensitization. The structure of the blue dye is designed on the basis of the red dye D35 (shown in Figure 1), which was previously found to be suitable with the cobalt-based redox couples. ${ }^{34}$ The introduction of the DPP structure into the blue dye gives a promising performance of $7.3 \%$ with cobalt electrolyte. The DB dye was found to have successful combination with D35 for co-sensitization. An improved efficiency of $8.7 \%$ was obtained for devices containing co-sensitized pure organic $\mathrm{D}-\pi-\mathrm{A}$ sensitizers and cobalt mediator.

\section{EXPERIMENTAL SECTION}

2.1. Synthesis of Dyenamo Blue (DB) Dye. Methods and materials follow. All reagents from commercial sources were used without further purification. ${ }^{1} \mathrm{H}$ and ${ }^{13} \mathrm{C}$ NMR spectra were recorded on Bruker 500 and $400 \mathrm{MHz}$ instruments by using the residual signal acetone- $d_{6} \delta=2.05,29.84$, and $206.26 \mathrm{ppm}$ as an internal reference for
${ }^{1} \mathrm{H}$ and ${ }^{13} \mathrm{C}$, respectively. Mass spectroscopy data were obtained using a Dionex UltiMate 3000 system with an electrospray ionization method. The solvent mixture used for direct injection was DCM:MeOH (1:1).

2.2. Solar Cell Assembly. Solar cells are assembled by the procedure which has been described in a previous report of our work. ${ }^{35}$ The $\mathrm{TiO}_{2}$ photoelectrodes, platinum decorated counter electrodes, and cobalt electrolyte were prepared as described and used in the previous report. The difference is mainly preparation of dye solutions. At a temperature of $90{ }^{\circ} \mathrm{C}$, the sintered $\mathrm{TiO}_{2}$ electrodes were immersed in a dye bath for $18 \mathrm{~h}$ containing D35 (0.2 mM), DB $(0.025 \mathrm{mM})$, or a mixture of D35 and DB by varied molar ratio in tertbutanol:acetonitrile $(1: 1 \mathrm{v} / \mathrm{v})$, respectively.

2.3. Solar Cells Characterization. All of the solar cell characterization methods performed in the present study are also described in our previous report. ${ }^{35}$ Basically, current-voltage (IV) characteristics were measured under a solar simulator (Newport, model 91160), which is controlled by a source measurement unit (Keithley 2400). A certified silicon solar cell (Fraunhofer ISE) was calibrated to an intensity of $100 \mathrm{~mW} \mathrm{~cm}^{-2}$ of a solar simulator (AM1.5 $\mathrm{G}$ spectral). Also, a black metal mask with area of $0.25 \mathrm{~cm}^{2}$ was used for all of the solar cells' characterization.

Incident photon-to-current conversion efficiency (IPCE) spectra measurements were conducted by a setup combining a xenon light source (Spectral Products ASB-XE-175), a monochromator (Spectral Products CM110), and a Keithley multimeter (model 2700). The silicon solar cell mentioned above is also calibrated with the IPCE spectra.

Electron lifetime and charge extraction measurements as a function of varied voltage at different bias light intensities was investigated in a "toolbox setup" as described previously. ${ }^{36,37}$ Mainly, the setup comprises a white LED (Luxeon Star 1W) as the light source, a 16bit resolution digital acquisition board (National Instruments) in combination with a current amplifier (Stanford Research Systems SR570), and a custom-made system using electromagnetic switches.

2.4. Electrochemical Measurements. A three-electrode cell was used for the cyclic voltammetry experiments. The supporting electrolyte used for electrochemical measurements was $0.10 \mathrm{M}$ $\mathrm{LiN}\left(\mathrm{CF}_{3} \mathrm{SO}_{2}\right)_{2}$ in acetonitrile. The counter electrode is a stainless steel plate with an area of $3 \mathrm{~cm}^{2}$. The reference electrode was $\mathrm{Ag} /$ $\mathrm{AgCl}$; a salt bridge electrolyte was interposed between working and reference electrodes, containing $0.10 \mathrm{M} \mathrm{LiN}\left(\mathrm{CF}_{3} \mathrm{SO}_{2}\right)_{2}$ in acetonitrile. The working electrode is a dye-sensitized $\mathrm{SnO}_{2}$ film with the thickness of $4 \mu \mathrm{m}$ and area of $0.25 \mathrm{~cm}^{2}$. The reference electrode was calibrated by recording the cyclic voltammogram of ferrocene in the same 
electrolyte; the potential values are on the basis of the estimated value of the ferrocene redox potential in acetonitrile $0.624 \mathrm{~V}$ versus SHE. ${ }^{38}$

2.5. Steady-State Absorption. $\mathrm{TiO}_{2}$ films for steady-state absorption measurements were prepared by $30 \mathrm{~nm}$ of $\mathrm{TiO}_{2}$ paste (Dyesol) with thickness of $2 \mu \mathrm{m}$ on microscope glass slides and sintering at $500{ }^{\circ} \mathrm{C}$. Absorption spectra were recorded on a HR-2000 Ocean Optics spectrophotometer with baseline correction.

For dye-loading calculation, transparent $\mathrm{TiO}_{2}$ films with the same properties as those used in the DSSCs were sensitized with the four different dye mixtures for $18 \mathrm{~h}$. Each film was then carefully washed and dried with air flow before being desorbed in $1 \mathrm{~mL}$ of $0.05 \mathrm{M}$ TBAOH (in 1:1 ACN:tBuOH). The absorbance was then measured with a HR-2000 Ocean Optics spectrophotometer and the amount of each dye calculated from standard curves obtained for this specific condition (see SI).

2.6. Nanosecond Transient Absorption Spectroscopy (TAS). Samples are prepared according to previous procedures. ${ }^{39}$ Basically, transparent $\mathrm{TiO}_{2}$ films were sensitized to act as the photocathode, while nonplatinized FTOs were used as the counter electrode. Two types of sensitized films were used in the present study: one is sensitized by DB dye, and another is sensitized by co-sensitized dyes (DB:D35 = 3:4), all of which assembled with either inert $(0.1 \mathrm{M}$ $\mathrm{LiClO}_{4}, 0.2 \mathrm{M} \mathrm{TBP}$ ) or redox electrolytes (the same electrolyte as described in the solar cell fabrication details).

TAS measurements were performed with a laser flash photolysis spectrometer (Edinburgh Instrument LP920), using a continuous wave xenon light as a probe light. Laser pulses were generated and tuned to $670 \mathrm{~nm}$, using a frequency tripled Nd:YAG laser (Continuum Surelight II, $10 \mathrm{~Hz}$ repetition rate, $10 \mathrm{~ns}$ pulse width) in combination with an OPO (Continuum Surelight). The pulse intensity was attenuated on the order of $0.1 \mathrm{~mJ} \mathrm{~cm}^{-2}$ per pulse using neutral density filters; therefore, only few electrons were injected into every $\mathrm{TiO}_{2}$ nanoparticle upon the pulse excitation of dye molecules. Kinetic traces were monitored at $750 \mathrm{~nm}$, where oxidized DB dye shows strong absorption indicated by PIA measurement (see Figure S7 in the Supporting Information). The signal was averaged from 100 to 500 measurements to reduce the noise.

2.7. Photoinduced Absorption Spectroscopy (PIA). PIA measurements were performed using the same setup as described in previous literature. ${ }^{40}$ Briefly, the absorption changes of the sample were probed by a $20 \mathrm{~W}$ tungsten-halogen lamp. A square-wave modulated blue LED $(460 \mathrm{~nm})$ with a frequency of $9.33 \mathrm{~Hz}$ was utilized to periodically excite the samples. The transmitted light through the samples was then focused on the monochromator, and detected by a $\mathrm{Si}$ photodiode during the time. The signal was further amplified with a current preamplifier and connected to a lock-in amplifier (Stanford Research Systems model 830 and 570, respectively). The excitation LED intensity was set to $\sim 8 \mathrm{~mW} / \mathrm{cm}^{2}$. This measurement is conducted to confirm the absorption spectrum of oxidized D35, DB, and co-sensitized $\mathrm{TiO}_{2}$ electrode (seen in Figure S7).

\section{RESULTS AND DISCUSSION}

3.1. Design and Synthesis of DB Dye. Prior to the synthesis, quantum chemical calculations (Figure 2) were performed to predict the properties of the sensitizers and provide guidance in the choice of target sensitizers. All of the alkyl chains were truncated to balance the efficiency of calculation and its accuracy. Gas-phase geometries were optimized by density functional theory at the B3LYP/6-311G (d, p) level using Gaussian09 software. Analytic frequency calculations were executed to ensure that the lowest vibrational frequencies were real, and an energy minimum was achieved. Time-dependent density functional theory (TD-DFT) was then utilized at the same theoretical level to find vertical transitions. The most likely transitions were found to be HOMO to LUMO $(f=0.71)$, with HOMO mainly located on the triphenylamine moiety and LUMO largely located at the
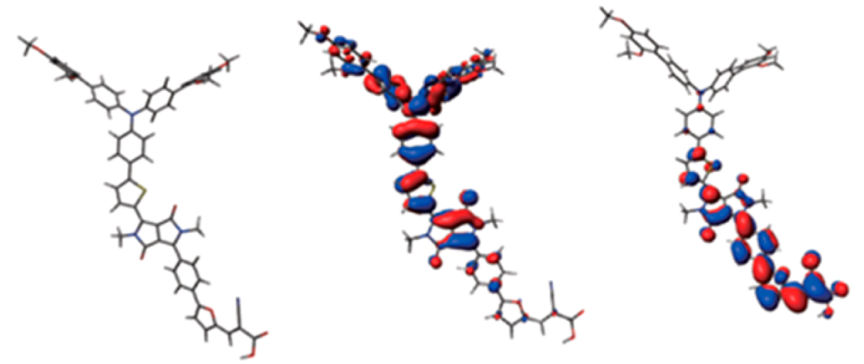

Figure 2. Optimized structure (left) of DB dye (with truncated alkyl chains), and the frontier molecular orbitals of the HOMO (middle) and LUMO (right) calculated with DFT at the B3LYP/6-311G(d,p) level in the gas phase.

carboxylic anchoring group, indicating a pronounced intramolecular charge separation after excitation.

The Dyenamo Blue dye was synthesized in the general synthetic route as shown in Scheme 1. The linker part which employed the DPP-core was synthesized first according to the method reported by Jun-Ho Yum, Thomas W. Holcombe, etc. $^{20}$ Then, the donor part of D35 (D35-D) was combined with the linker part (D) by Suzuki coupling reaction. Further, the final dye was synthesized by condensation of aldehydes with cyanoacetic acid by the Knoevenagel reaction. The characterizations of the new compounds and also the details of synthesis are described in the Supporting Information section.

3.2. Photophysical and Electrochemical Properties. The absorption spectra of the DB dye dissolved in tertbutanol:acetonitrile $(1: 1 \mathrm{v} / \mathrm{v})$ solution with different concentrations are illustrated in Figure S1, while the spectrum of the sensitized $\mathrm{TiO}_{2}$ film is shown in Figure $3 \mathrm{a}$ (blue line). The maximum absorption peaks of the $\mathrm{DB}$ dye are located at 571 $\mathrm{nm}$ in solution and $564 \mathrm{~nm}$ on $\mathrm{TiO}_{2}$ film, respectively. The absorption of the dye ranges from the UV to about $700 \mathrm{~nm}$, both in solution and on the film, with a pronounced dip around $450 \mathrm{~nm}$. The data showed the wide absorption of the DB dye and the capability of absorbing the photons in the long wavelength which is almost up to the NIR region. The photophysical and electrochemical details of the novel DB dye can be found in Table 1 .

The absorbance spectra obtained from the D35-sensitized (red line) and dye-mixture-sensitized (DB $0.075 \mathrm{mM}$, D35 0.10 $\mathrm{mM}$, black line) $\mathrm{TiO}_{2}$ films were presented in Figure 3a. With the co-sensitization strategy, the whole visible range was successfully covered. The improvement of the absorption spectra promoted the utilization of light, which further suggested a better DSSC performance.

The formal reduction and oxidation potentials of $\mathrm{D} 35, \mathrm{DB}$, and co-sensitized (DB:D35 = 3:4) dyes adsorbed on nanocrystalline $\mathrm{Sb}$-doped $\mathrm{SnO}_{2}$ electrodes were measured and shown in Figure $3 \mathrm{~b}$ and Table 1 . The novel DB dye has a slightly less positive HOMO level than that of D35, which is $1.08 \mathrm{~V}$ versus SHE compared to $1.12 \mathrm{~V}$ versus SHE for D35. The lower HOMO of $\mathrm{DB}$ could be ascribed to the larger conjugated system of DB, whereas the slightly lower driving force (the potential difference between the dye and cobalt mediator) is still enough for fast regeneration kinetics between DB dye and cobalt mediator in DSSCs. ${ }^{41}$ Moreover, the cosensitized D35 and DB dyes in a ratio of 3:4 show a HOMO level similar to that of the DB dye, which also satisfies the requirement of electron transfer between the oxidized dye and redox mediator. 
Scheme 1. Synthetic Route of DB Dye ${ }^{a}$
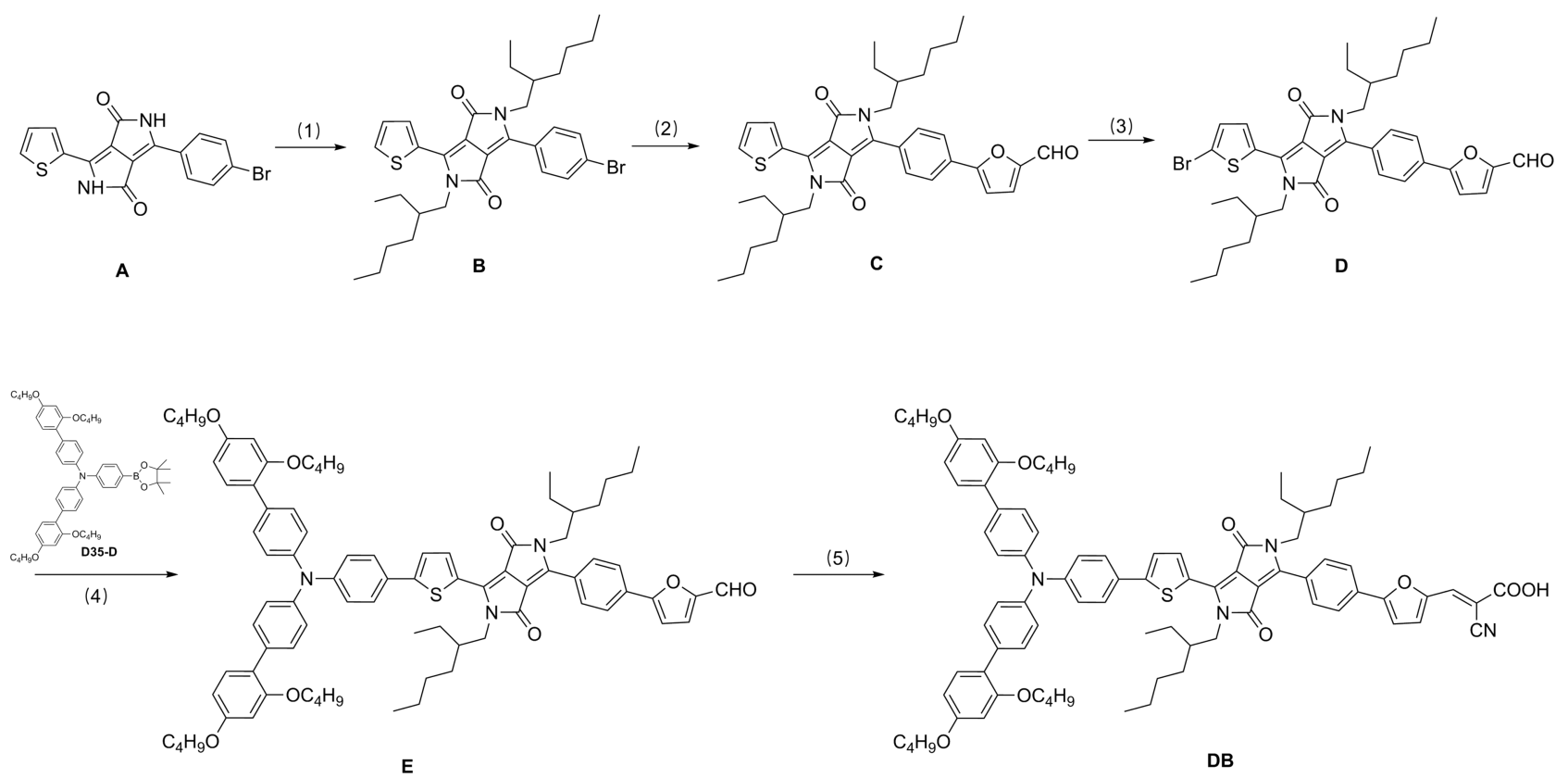

${ }^{a}$ (1) 3-(Bromomethyl)heptane, $\mathrm{K}_{2} \mathrm{CO}_{3}$ in $\mathrm{DMF}, 90^{\circ} \mathrm{C}$, overnight, 73\%; (2) (5-formylfuran-2-yl)boronic acid, toluene: $\mathrm{MeOH} \mathrm{Pd}(\mathrm{dppt}) \mathrm{Cl}{ }_{2}, 70{ }^{\circ} \mathrm{C}$, $1 \mathrm{~h}, 80 \%$; (3) NBS, CHCl 3 , RT, 4 h, 53\%; (4) 2',4'-dibutoxy- $N$-(2',4'-dibutoxy-[1,1'-biphenyl]-4-yl)-N-(4-(4,4,5,5-tetramethyl-1,3,2-dioxaborolan-2yl)phenyl)-[1,1'-biphenyl]-4-amine (D35-D), $\mathrm{K}_{3} \mathrm{PO}_{4}$, toluene, $\mathrm{Pd}_{2} \mathrm{dba}_{3}$ X-Phos (2-dicyclohexylphosphino-2', $4^{\prime}, 6^{\prime}$-triisopropylbiphenyl), XPhos Pd G3 ((2-dicyclohexylphosphino-2' ${ }^{\prime} 4^{\prime}, 6^{\prime}$-triisopropyl-1,1'-biphenyl) [2-(2'-amino-1,1'-biphenyl)]palladium(II) methanesulfonate), $80{ }^{\circ} \mathrm{C}, 6 \mathrm{~h}, 53 \%$; (5) cyanoacetic acid, $\mathrm{MeCN}: \mathrm{CHCl}_{3}$, piperidine, $80{ }^{\circ} \mathrm{C}, 2 \mathrm{~h}, 44 \%$.

3.3. DSSCs. The photovoltaic performances of DSSCs based on the individual dyes as well as the best co-sensitization composition (DB:D35 = 3:4 (0.075 mM:0.1 mM in dye bath)) are presented in Table 2 and Figure 4a. A relatively thin, transparent $\mathrm{TiO}_{2}$ film $(4 \mu \mathrm{m})$ with scattering $\mathrm{TiO}_{2}$ layer (4 $\mu \mathrm{m})$ was used in this work to decrease mass transport problems that happened in cobalt complex mediator-based DSSCs. According to the data, the DSSC devices with DB dye generate $40 \%$ more photocurrent than that of the D35-sensitized devices for their broader absorption. However, the open-circuit potential is lower for the devices with DB dye, which suggested the higher recombination between the electrons in $\mathrm{TiO}_{2}$ and $\mathrm{Co}$ (III) species in the electrolyte, and/or to oxidized dyes, indicating the less efficient blocking effect of DB dye. The overall power conversion efficiency (PCE) of the device with $\mathrm{DB}$ is higher $(7.3 \%)$ than that of D35 (5.5\%). Further, the improved performance of solar cells, $8.7 \%$, was reached by cosensitization with the molar ratio of 3:4 (DB:D35).

Different molar ratios and concentrations of DB:D35 in the dye bath have been performed, before the best composition of the co-sensitized system for photovoltaic performance was achieved. The solar cell parameters from different combinations are shown in Table S1. Initially, the concentration of D35 varied from 0.025 to $0.2 \mathrm{mM}$ with a constant concentration of $\mathrm{DB}$ as $0.025 \mathrm{mM}$. As a result of the increasing concentration of D35 in the dye bath, the $V_{\mathrm{OC}}$ of the devices increased markedly (rows 1-3 in Table S1). The reason for this might be that, with D35 as co-sensitizer, the blocking effect was improved; therefore, the recombination between the electrons in $\mathrm{TiO}_{2}$ and the electrolyte was reduced. Then, in contrast, the concentration of D35 was fixed $(0.1 \mathrm{mM})$, and the concentration of DB was increased from 0.025 to $0.1 \mathrm{mM}$ (rows 2 and 4-6 in Table S1). This time, there are only minor changes in the $V_{\mathrm{OC}}$, while the photocurrents are very different; the optimum photocurrent was found with $0.075 \mathrm{mM} \mathrm{DB}$. This could be explained by the broader absorption spectrum of $\mathrm{DB}$. With higher concentration of DB dye in the dye bath, an improved IPCE can be observed in the further red part of the IPCE spectrum (the discussion could be found in below, see Figure S6).

Figure $4 \mathrm{~b}$ illustrates the incident photon-to-current efficiency (IPCE) spectra of the DSSCs, which are sensitized by the individual dyes $\mathrm{D} 35, \mathrm{DB}$, and the co-sensitized dyes at the best condition (DB:D35 = 3:4). The IPCEs of the DSSCs sensitized by $\mathrm{D} 35$ and $\mathrm{DB}$ are located in the ranges $400-650$ and 500$750 \mathrm{~nm}$, respectively. The co-sensitized IPCE curve, showing the complementary behavior of the D35 and DB dyes, gives an enhanced and broader IPCE response compared to the single dye, resulting in an improved $J_{S C}$ and the photovoltaic efficiency. The IPCE values obtained in Figure $4 \mathrm{~b}$ are consistent with the photovoltic performance presented in Figure $4 \mathrm{a}$, showing the advantage of co-sensitized strategy.

Photovoltage response time measurements were performed in dependence of the light intensity in order to determine electron lifetime. As shown in Figure 5a, at a given potential, the electron lifetime of DB-sensitized solar cells is much shorter (by about 2 orders of magnitude) than that of D35. This corresponds to a higher recombination rate of electrons in the $\mathrm{TiO}_{2}$ with $\mathrm{Co}(\mathrm{III})$ species in the electrolyte in DB-based devices. ${ }^{42}$ No significant shift of the conduction band edge was found (by charge extraction measurement seen in Figure $5 b$ ). The electron-blocking properties of $\mathrm{DB}$ are thus poor in comparison to those of D35. This is likely related to the relatively lower dye coverage of $\mathrm{DB}$ in comparison to D35 (details can be found in the latter part of this article, see Table 

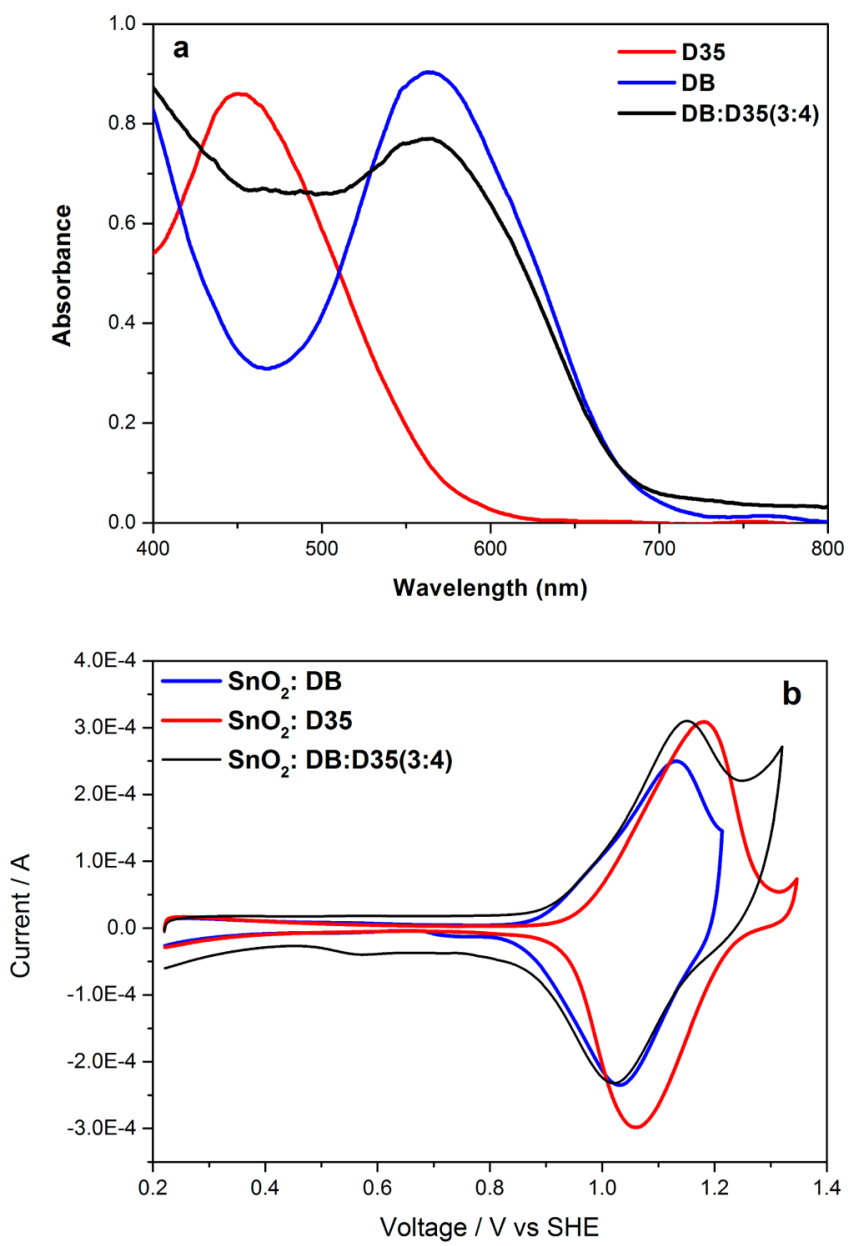

Figure 3. (a) UV-vis spectra of D35, DB, and co-sensitized (DB:D35 $=3: 4$ ) dyes on $\mathrm{TiO}_{2}$ mesoporous film $(2 \mu \mathrm{m})$. (b) Cyclic voltammetry of D35, DB, and co-sensitized (DB:D35 = 3:4) dyes adsorbed on nanocrystalline $\mathrm{Sb}$-doped $\mathrm{SnO}_{2}$ electrodes.

3). This would leave uncovered $\mathrm{TiO}_{2}$ surface sites, which can promote electron recombination.

By the co-sensitization strategy, significantly longer electron lifetimes were found in comparison with that of the individual DB sensitization. This was caused by the better $\mathrm{TiO}_{2}$ blocking with additional D35, the dye which has been demonstrated to have excellent blocking properties with cobalt electrolyte in earlier work. ${ }^{34}$ The new co-sensitization between DB and D35 leads to an improved blocking effect of the dye monolayer, which decreases the electron recombination rate between $\mathrm{TiO}_{2} /$ dye and the electrolyte. However, there is still much room for improvement, and better combinations of dyes are expected to be found in future work.
Table 2. Photovoltaic Performance of DSSCs Based on the D35, DB, and Co-Sensitized Dyes (DB:D35 = 3:4) under $1000 \mathrm{~W} \mathrm{~m}^{-2} \mathrm{AM} 1.5 \mathrm{G}$ Illumination

\begin{tabular}{lcccc}
\multicolumn{1}{c}{ dye } & $V_{\mathrm{OC}}(\mathrm{mV})$ & $J_{\mathrm{SC}}\left(\mathrm{mA} / \mathrm{cm}^{2}\right)$ & $\mathrm{FF}(\%)$ & $\eta(\%)$ \\
D35 & 853 & 9.14 & 70.3 & 5.5 \\
DB & 757 & 13.21 & 72.7 & 7.3 \\
DB/D35 = 3:4 & 797 & 15.60 & 70.1 & 8.7 \\
\hline
\end{tabular}
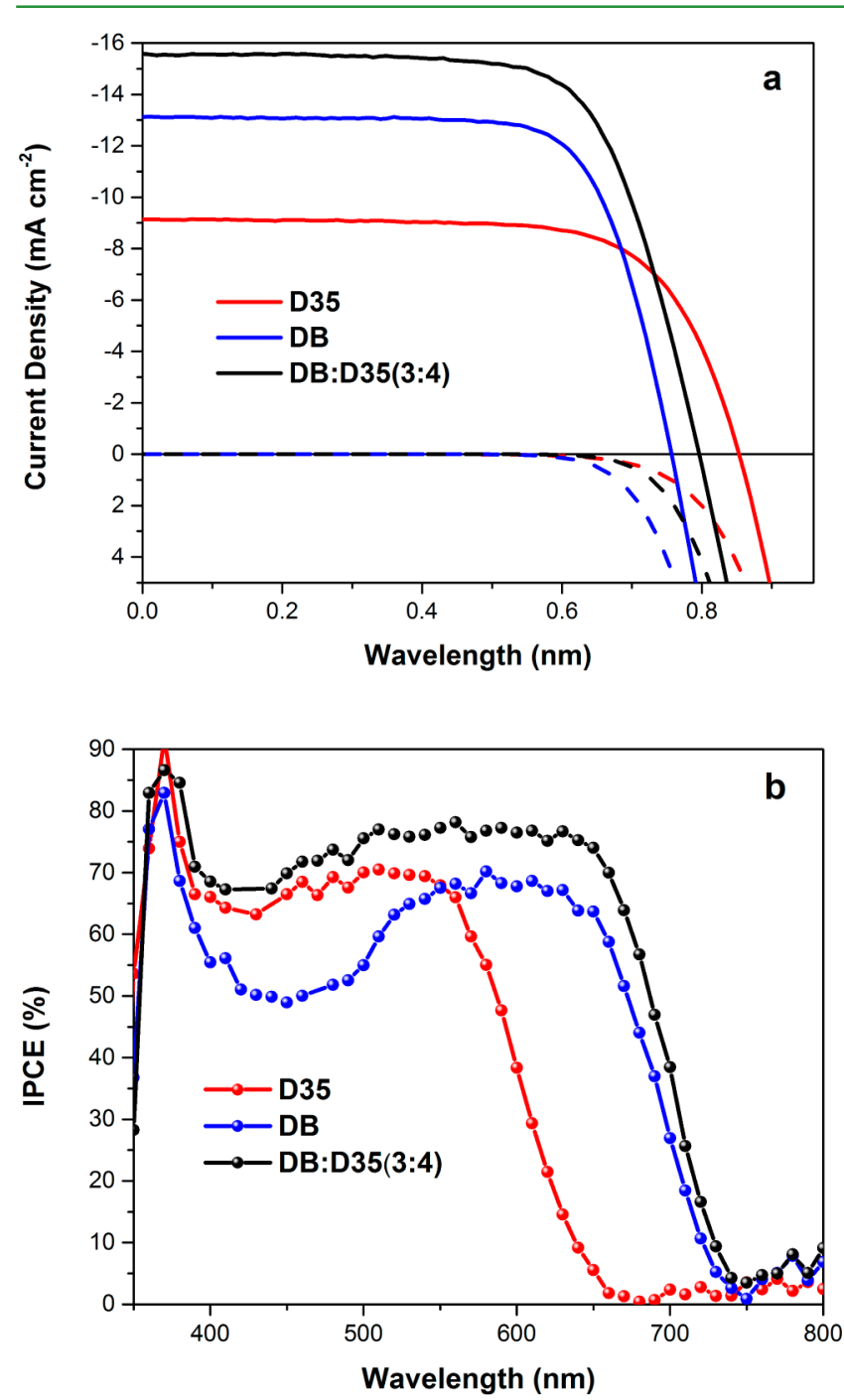

Figure 4. (a) Current density versus applied potential curves under $1000 \mathrm{~W} \mathrm{~m}^{-2}$ AM1.5 $\mathrm{G}$ illumination (dot lines) and in darkness (dashed lines). (b) Spectra of incident photon-to-current conversion efficiency (IPCE) for DSSCs based on D35, DB, and co-sensitized dyes (DB:D35 = 3:4).

Table 1. Photophysical and Electrochemical Properties of the DB Dye

\begin{tabular}{|c|c|c|c|c|c|c|}
\hline \multicolumn{3}{|c|}{ absorption } & emission $^{b}$ & \multirow[b]{2}{*}{$E_{0-0}^{c}(\mathrm{~V})$} & \multirow[b]{2}{*}{$E_{\mathrm{ox}}{ }^{d}(\mathrm{~V}$ vs NHE) } & \multirow[b]{2}{*}{$E_{\mathrm{ox}}-E_{0-0}(\mathrm{~V}$ vs $\mathrm{NHE})$} \\
\hline$\lambda_{\max }^{a}(\mathrm{~nm})$ & $\varepsilon$ at $\lambda_{\max }\left(\mathrm{M}^{-1} \mathrm{~cm}^{-1}\right)$ & $\lambda_{\max }$ on $\mathrm{TiO}_{2}(\mathrm{~nm})$ & $\lambda_{\max }(\mathrm{nm})$ & & & \\
\hline 571 & 33640 & 564 & 725 & 1.95 & 1.08 & -0.87 \\
\hline
\end{tabular}

${ }^{a}$ Absorption spectra were measured in the solution of tert-butanol:acetonitrile $=1: 1$ with different concentrations at $25^{\circ} \mathrm{C}$. ${ }^{b}$ Emission spectra were measured in tert-butanol:acetonitrile $=1: 1$ solutions $\left(1 \times 10^{-6} \mathrm{M}\right)$ at $25^{\circ} \mathrm{C}$. ${ }^{c}$ The zeroth-zeroth transition $\left(E_{0-0}\right)$ value was estimated from the intersection of the absorption and emission spectra (Figure S2). ${ }^{d}$ Cyclic voltammetry of the oxidation behavior of the dyes was measured on SnO ${ }_{2}$ film containing $0.1 \mathrm{M} \mathrm{LiN}\left(\mathrm{CF}_{3} \mathrm{SO}_{2}\right)_{2}$ in acetonitrile as supporting electrolyte (working electrode, dye-sensitized $\mathrm{SnO}_{2}$ film; reference electrode, $\mathrm{Ag}$ / $\mathrm{Ag}^{+}$calibrated with ferrocene/ferrocenium $\left(\mathrm{Fc} / \mathrm{Fc}^{+}\right)$as an internal reference; counter electrode, a stainless steel plate). 

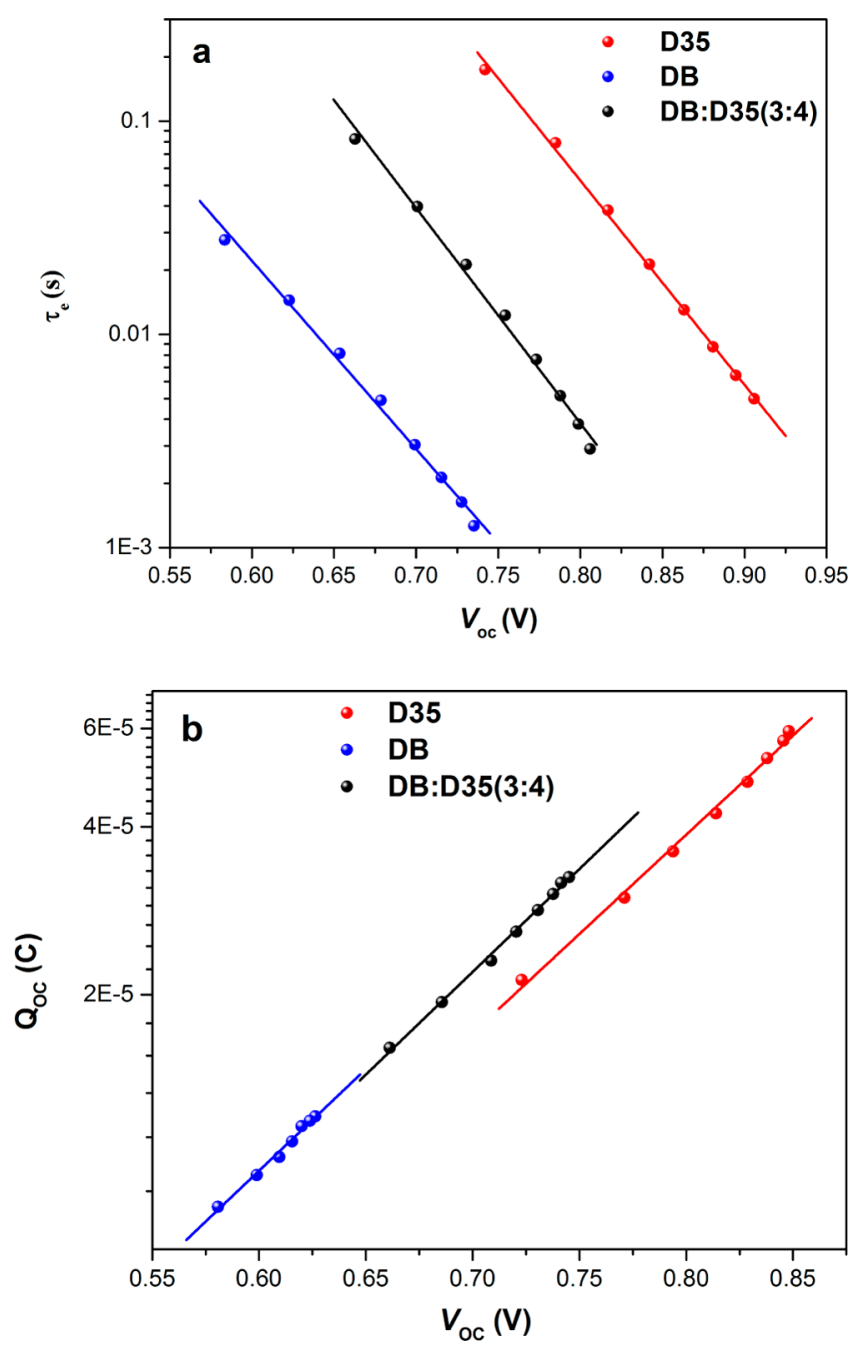

Figure 5. (a) Electron lifetime and (b) accumulation charge as a function of the $V_{\mathrm{OC}}$ under open-circuit conditions for DSSCs sensitized with D35, DB, and co-sensitized dyes employing cobalt electrolyte.

Table 3. Dye-Loading Measurements of Single and CoSensitized $\mathrm{TiO}_{2}$ Films ${ }^{a}$

\begin{tabular}{|c|c|c|c|c|}
\hline $\begin{array}{c}\text { dye } \\
\text { concentration in } \\
\text { solution } \\
\text { (DB:D35) }\end{array}$ & $n \mathrm{D} 35(\mathrm{nmol})$ & $n \mathrm{DB}(\mathrm{nmol})$ & dye ${ }^{\text {total }}(\mathrm{nmol})$ & $\begin{array}{l}\text { dye ratio on } \\
\text { films } \\
\text { (DB:D35) }\end{array}$ \\
\hline $\begin{array}{l}0 \mathrm{mM}: 0.2 \mathrm{mM} \\
(0: 1)\end{array}$ & $20.2 \pm 0.9$ & 0 & $20.2 \pm 0.9$ & \\
\hline $\begin{array}{c}0.025 \mathrm{mM}: 0.2 \\
\mathrm{mM}(1: 8)\end{array}$ & $16.6 \pm 0.7$ & $2.8 \pm 0.1$ & $19.4 \pm 0.8$ & $1: 6$ \\
\hline $\begin{array}{c}0.025 \text { mM:0.1 } \\
\text { mM (1:4) }\end{array}$ & $15.5 \pm 0.6$ & $4.5 \pm 0.2$ & $20.0 \pm 0.8$ & $2: 7$ \\
\hline $\begin{array}{c}0.05 \mathrm{mM}: 0.1 \\
\mathrm{mM}(1: 2)\end{array}$ & $13.4 \pm 0.5$ & $8.5 \pm 0.3$ & $21.9 \pm 0.8$ & $2: 3$ \\
\hline $\begin{array}{c}0.075 \text { mM:0.1 } \\
\text { mM (3:4) }\end{array}$ & $11.9 \pm 0.6$ & $11.1 \pm 0.4$ & $23.0 \pm 1.0$ & $1: 1$ \\
\hline $\begin{array}{l}0.025 \mathrm{mM}: 0 \\
(1: 0)\end{array}$ & 0 & $8.2 \pm 0.3$ & $8.2 \pm 0.3$ & \\
\hline
\end{tabular}

3.4. Dye-Loading Properties. By different co-sensitization conditions, the absorption spectrum of the film can be changed, as well as the dye stacking patterns. Some characterizations have been conducted to investigate how the co-sensitization system works on the basis of the varied molar ratio of DB and D35. Figure S5 (top) shows the UV-vis absorption spectra of $\mathrm{TiO}_{2}$ films $(2 \mu \mathrm{m})$ with different co-sensitization conditions. It is obvious to see that the maxima of the absorption peaks of the individual dyes are related to the dye bath ratios; especially, the DB dye peak is becoming larger with an increased concentration of $\mathrm{DB}$, accompanied with the declining absorption peak of D35. In order to gain a deeper insight about the actual dye load on the sensitized films, the sensitized dye was desorbed in $0.05 \mathrm{M}$ TBAOH (1:1 tert-butanol:acetonitrile) followed by absorbance measurements of the solution (Figure S5 (bottom)). The results of the dye desorption measurements are summarized in Table 3, where the amount of each dye loaded on the film and the film ratio (DB:D35) are presented for each co-sensitization composition. Here it becomes even clearer that the DB dye has a larger affinity to the $\mathrm{TiO}_{2}$ electrode than $\mathrm{D} 35$, since the relative amount of D35 on the film always becomes smaller than in the dye bath. At the molar ratio of 3:4 (DB:D35) in the dye bath, in which the best performance was achieved, the two dyes has almost equal amounts of molecules adsorbed on the $\mathrm{TiO}_{2}$ film. The IPCE spectra of DSSCs which are co-sensitized give consistent hints of the relative amount of D35 and DB on the surface (Figure S6).

3.5. Kinetics. The transient absorption kinetics of DB and co-sensitized DB:D35 on $\mathrm{TiO}_{2}$ electrodes were also investigated. The experiments were either conducted with inert electrolyte or in contact with the redox-couple-based electrolyte, on a nano- to millisecond time scale (see Figure 6 and Table 4). An excitation wavelength of $670 \mathrm{~nm}$ was used to exclusively excite the DB molecules. Under the conditions used, the transfer of electrons from the mesoporous $\mathrm{TiO}_{2}$ to oxidized DB molecules occurred with a half time $\left(t_{1 / 2}\right)$ of $5.75 \mu \mathrm{s}$. In comparison, this process occurred significantly slower with half time of $8.27 \mu$ s for co-sensitized $\mathrm{TiO}_{2}$ electrodes. Here, slower electron-oxidized dye recombination kinetics is preferred. Under operational conditions, the concentration of electrons in the mesoporous $\mathrm{TiO}_{2}$ is high. Therefore, the electronoxidized dye recombination will result in significant energy losses, which is negative for the solar cell performance. The device with the co-sensitization system showed sluggish electron-oxidized dye recombination kinetics here. This is favorable for solar cell performance; moreover, this also confirms the exceptional blocking effect by additional D35 with DB dye. The better blocking effect may correlate to the binding mode of both $\mathrm{DB}$ and $\mathrm{D} 35$ dyes on the $\mathrm{TiO}_{2}$ surface, which probably would be because one dye affects the orientation of another dye on the $\mathrm{TiO}_{2}$ surface. The different orientation is likely to decrease the electron transfer reaction rate between electrons in $\mathrm{TiO}_{2}$ and the location of the "hole" in the oxidized dye, in the triphenyl amine group. In combination with the cobalt-based electrolyte, similar regeneration kinetics were found for the DB and co-sensitized DSSCs. This indicates that the additional D35 did not slow down the electron transfer between oxidized sensitizer and redox species inside the electrolyte.

\section{CONCLUSIONS}

A novel blue $\mathrm{D}-\pi-\mathrm{A}$ organic sensitizer (DB) was designed and synthesized for DSSCs with cobalt-based redox. With this blue dye, an energy conversion efficiency of $7.3 \%$ was yielded, under one sun AM1.5 G. The co-sensitization strategy was applied with an additional D35 dye. The device with co-sensitized dyes 

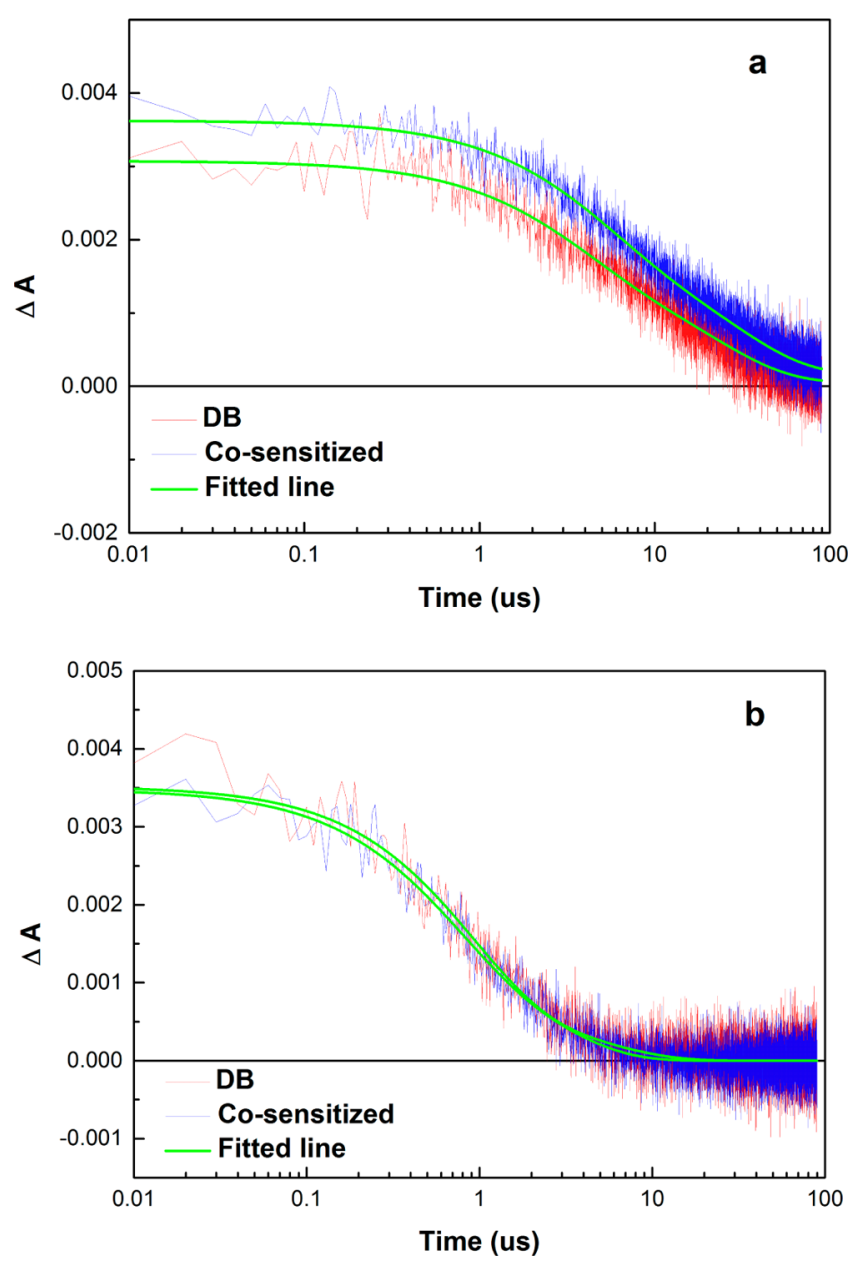

Figure 6. Transient absorption kinetics of $\mathrm{TiO}_{2}$ sensitized with $\mathrm{DB}$ (blue line) and co-sensitized (DB:D35 = 3:4) (red line) under the condition of inert electrolyte (a) and cobalt bipyridine electrolyte (b).

Table 4. Measured Halftimes and Calculated Regeneration Efficiencies for DB-Sensitized and Co-Sensitized (DB:D35 = 3:4) DSSCs Employing Cobalt Bipyridine Redox Couple

\begin{tabular}{lccc}
\multicolumn{1}{c}{ sample } & $t_{1 / 2 \text { redox }}(\mu \mathrm{s})$ & $t_{1 / 2 \text { inert }}(\mu \mathrm{s})$ & $\eta_{\text {reg }}(\%)$ \\
DB & $0.7 \pm 0.1$ & $5.8 \pm 0.5$ & $89 \pm 1$ \\
DB:D35 = 3:4 & $0.7 \pm 0.1$ & $8.3 \pm 0.8$ & $91 \pm 1$ \\
\hline
\end{tabular}

achieved a PCE of $8.7 \%$ with a greater current density from the complementary absorption. This performance is superior to either of the individual devices sensitized by DB (7.3\%) or D35 (5.5\%) under the same fabrication condition. The additional D35 was found to decrease the recombination at the interface between $\mathrm{TiO}_{2} /$ dye and electrolyte, as well as the recombination between the electrons in $\mathrm{TiO}_{2}$ and oxidized dyes. This work shows the possibility of using two pure organic dyes with very different absorbing spectra together with cobalt complex-based redox. This co-sensitization greatly uses the light in solar spectra, and at the same time increases the blocking effect on the $\mathrm{TiO}_{2}$ surface. The results indicate that, by proper design of dyes, the performance of DSSCs can be further improved by the co-sensitization strategy.

\section{ASSOCIATED CONTENT}

\section{Supporting Information}

The Supporting Information is available free of charge on the ACS Publications website at DOI: 10.1021/acsami.6b09671.

Detailed synthesis, characterization of synthesized mediators and sensitizer (DB dye), UV-vis absorption, solar cell performances and IPCE spectra, and PIA and TAS figures (PDF)

\section{AUTHOR INFORMATION}

\section{Corresponding Author}

*E-mail: gerrit.boschloo@kemi.uu.se.

\section{Notes}

The authors declare no competing financial interest.

\section{ACKNOWLEDGMENTS}

We gratefully acknowledge the Swedish Energy Agency, the Swedish Research Council (VR), the STandUP for Energy program, the Knut and Alice Wallenberg Foundation, Stiftelsen Olle Engkvist Byggmätare, and the Swiss National Science Foundation Contract 200021_157135/1 "Fundamental studies of mesoscopic devices for solar energy conversion” for financial support. Dr. Martin Karlsson and Dr. Palas Baran Pati are acknowledged for their help with characterization of the novel blue dye.

\section{REFERENCES}

(1) O’Regan, B.; Gratzel, M. A Low-Cost, High-Efficiency Solar Cell based on Dye-Sensitized Colloidal $\mathrm{TiO}_{2}$ Films. Nature 1991, 353, $737-740$.

(2) Zhang, S.; Yang, X.; Numata, Y.; Han, L. Highly Efficient DyeSensitized Solar Cells: Progress and Future Challenges. Energy Environ. Sci. 2013, 6, 1443-1464.

(3) Graetzel, M.; Janssen, R. A. J.; Mitzi, D. B.; Sargent, E. H. Materials Interface Engineering for Solution-Processed Photovoltaics. Nature 2012, 488, 304-312.

(4) Soni, S. S.; Fadadu, K. B.; Vaghasiya, J. V.; Solanki, B. G.; Sonigara, K. K.; Singh, A.; Das, D.; Iyer, P. K. Improved Molecular Architecture of D- $\pi$-A Carbazole Dyes: 9\% PCE with A Cobalt Redox Shuttle in Dye Sensitized Solar Cells. J. Mater. Chem. A 2015, 3, 21664-21671.

(5) Hamann, T. W. The End of Iodide? Cobalt Complex Redox Shuttles in DSSCs. Dalton Trans. 2012, 41, 3111-3115.

(6) Burke, A.; Schmidt-Mende, L.; Ito, S.; Gratzel, M. A Novel Blue Dye for Near-IR 'Dye-Sensitised' Solar Cell Applications. Chem. Commun. 2007, 3, 234-236.

(7) Paek, S.; Choi, H.; Kim, C.; Cho, N.; So, S.; Song, K.; Nazeeruddin, M. K.; Ko, J. Efficient and Stable Panchromatic Squaraine Dyes for Dye-Sensitized Solar Cells. Chem. Commun. 2011, 47, 2874-2876.

(8) Park, J.; Barolo, C.; Sauvage, F.; Barbero, N.; Benzi, C.; Quagliotto, P.; Coluccia, S.; Di Censo, D.; Gratzel, M.; Nazeeruddin, M. K.; Viscardi, G. Symmetric vs. Asymmetric Squaraines as Photosensitisers in Mesoscopic Injection Solar Cells: a StructureProperty Relationship Study. Chem. Commun. 2012, 48, 2782-2784.

(9) Shi, Y.; Hill, R. B. M.; Yum, J.-H.; Dualeh, A.; Barlow, S.; Grätzel, M.; Marder, S. R.; Nazeeruddin, M. K. A High-Efficiency Panchromatic Squaraine Sensitizer for Dye-Sensitized Solar Cells. Angew. Chem., Int. Ed. 2011, 50, 6619-6621.

(10) Yum, J.-H.; Walter, P.; Huber, S.; Rentsch, D.; Geiger, T.; Nüesch, F.; De Angelis, F.; Grätzel, M.; Nazeeruddin, M. K. Efficient Far Red Sensitization of Nanocrystalline $\mathrm{TiO}_{2}$ Films by an Unsymmetrical Squaraine Dye. J. Am. Chem. Soc. 2007, 129, 1032010321. 
(11) Geiger, T.; Kuster, S.; Yum, J.-H.; Moon, S.-J.; Nazeeruddin, M. K.; Grätzel, M.; Nüesch, F. Molecular Design of Unsymmetrical Squaraine Dyes for High Efficiency Conversion of Low Energy Photons into Electrons Using $\mathrm{TiO}_{2}$ Nanocrystalline Films. Adv. Funct. Mater. 2009, 19, 2720-2727.

(12) Kanaparthi, R. K.; Kandhadi, J.; Giribabu, L. Metal-Free Organic Dyes for Dye-Sensitized Solar Cells: Recent Advances. Tetrahedron 2012, 68, 8383-8393.

(13) Cid, J.-J.; Yum, J.-H.; Jang, S.-R.; Nazeeruddin, M. K.; MartínezFerrero, E.; Palomares, E.; Ko, J.; Grätzel, M.; Torres, T. Molecular Cosensitization for Efficient Panchromatic Dye-Sensitized Solar Cells. Angew. Chem., Int. Ed. 2007, 46, 8358-8362.

(14) de la Torre, G.; Claessens, C. G.; Torres, T. Phthalocyanines: Old Dyes, New Materials. Putting Color in Nanotechnology. Chem. Commun. 2007, 2000-2015.

(15) Garcia-Iglesias, M.; Cid, J.-J.; Yum, J.-H.; Forneli, A.; Vazquez, P.; Nazeeruddin, M. K.; Palomares, E.; Gratzel, M.; Torres, T. Increasing the Efficiency of Zinc-Phthalocyanine based Solar Cells through Modification of the Anchoring Ligand. Energy Environ. Sci. 2011, 4, 189-194.

(16) Shibano, Y.; Umeyama, T.; Matano, Y.; Imahori, H. ElectronDonating Perylene Tetracarboxylic Acids for Dye-Sensitized Solar Cells. Org. Lett. 2007, 9, 1971-1974.

(17) Edvinsson, T.; Li, C.; Pschirer, N.; Schöneboom, J.; Eickemeyer, F.; Sens, R; Boschloo, G.; Herrmann, A.; Müllen, K.; Hagfeldt, A. Intramolecular Charge-Transfer Tuning of Perylenes: Spectroscopic Features and Performance in Dye-Sensitized Solar Cells. J. Phys. Chem. C 2007, 111, 15137-15140.

(18) Imahori, H.; Umeyama, T.; Ito, S. Large $\pi$-Aromatic Molecules as Potential Sensitizers for Highly Efficient Dye-Sensitized Solar Cells. Acc. Chem. Res. 2009, 42, 1809-1818.

(19) Mori, S.; Nagata, M.; Nakahata, Y.; Yasuta, K.; Goto, R.; Kimura, M.; Taya, M. Enhancement of Incident Photon-to-Current Conversion Efficiency for Phthalocyanine-Sensitized Solar Cells by 3D Molecular Structuralization. J. Am. Chem. Soc. 2010, 132, 4054-4055. (20) Yum, J.-H.; Holcombe, T. W.; Kim, Y.; Rakstys, K.; Moehl, T.; Teuscher, J.; Delcamp, J. H.; Nazeeruddin, M. K.; Grätzel, M. BlueColoured Highly Efficient Dye-Sensitized Solar Cells by Implementing the Diketopyrrolopyrrole Chromophore. Sci. Rep. 2013, 3, 2446.

(21) Fan, S.-Q.; Kim, C.; Fang, B.; Liao, K.-X.; Yang, G.-J.; Li, C.-J.; Kim, J.-J.; Ko, J. Improved Efficiency of over $10 \%$ in Dye-Sensitized Solar Cells with a Ruthenium Complex and an Organic Dye Heterogeneously Positioning on a Single $\mathrm{TiO}_{2}$ Electrode. J. Phys. Chem. C 2011, 115, 7747-7754.

(22) Lan, C.-M.; Wu, H.-P.; Pan, T.-Y.; Chang, C.-W.; Chao, W.-S.; Chen, C.-T.; Wang, C.-L.; Lin, C.-Y.; Diau, E. W.-G. Enhanced Photovoltaic Performance with Co-sensitization of Porphyrin and an Organic Dye in Dye-Sensitized Solar Cells. Energy Environ. Sci. 2012, 5, 6460-6464.

(23) Kuang, D.; Walter, P.; Nüesch, F.; Kim, S.; Ko, J.; Comte, P.; Zakeeruddin, S. M.; Nazeeruddin, M. K.; Grätzel, M. Co-sensitization of Organic Dyes for Efficient Ionic Liquid Electrolyte-Based DyeSensitized Solar Cells. Langmuir 2007, 23, 10906-10909.

(24) Yum, J.-H.; Jang, S.-R.; Walter, P.; Geiger, T.; Nuesch, F.; Kim, S.; Ko, J.; Gratzel, M.; Nazeeruddin, M. K. Efficient Co-sensitization of Nanocrystalline $\mathrm{TiO}_{2}$ films by Organic Sensitizers. Chem. Commun. 2007, 4680-4682.

(25) Clifford, J. N.; Forneli, A.; Chen, H.; Torres, T.; Tan, S.; Palomares, E. Co-sensitized DSCs: Dye Selection Criteria for Optimized Device Voc and Efficiency. J. Mater. Chem. 2011, 21, $1693-1696$.

(26) Ning, Z.; Fu, Y.; Tian, H. Improvement of Dye-Sensitized Solar Cells: What We Know and What We Need to Know. Energy Environ. Sci. 2010, 3, 1170-1181.

(27) Wang, Y.; Chen, B.; Wu, W.; Li, X.; Zhu, W.; Tian, H.; Xie, Y. Efficient Solar Cells Sensitized by Porphyrins with an Extended Conjugation Framework and a Carbazole Donor: From Molecular Design to Cosensitization. Angew. Chem., Int. Ed. 2014, 53, 1077910783.
(28) Sun, X.; Wang, Y.; Li, X.; Agren, H.; Zhu, W.; Tian, H.; Xie, Y. Cosensitizers for Simultaneous Filling up of Both Absorption Valleys of Porphyrins: a Novel Approach for Developing Efficient Panchromatic Dye-Sensitized Solar Cells. Chem. Commun. 2014, 50, 15609-15612.

(29) Wei, T.; Sun, X.; Li, X.; Ågren, H.; Xie, Y. Systematic Investigations on the Roles of the Electron Acceptor and Neighboring Ethynylene Moiety in Porphyrins for Dye-Sensitized Solar Cells. ACS Appl. Mater. Interfaces 2015, 7, 21956-21965.

(30) Xie, Y.; Tang, Y.; Wu, W.; Wang, Y.; Liu, J.; Li, X.; Tian, H.; Zhu, W.-H. Porphyrin Cosensitization for a Photovoltaic Efficiency of 11.5\%: A Record for Non-Ruthenium Solar Cells Based on Iodine Electrolyte. J. Am. Chem. Soc. 2015, 137, 14055-14058.

(31) Yella, A.; Lee, H.-W.; Tsao, H. N.; Yi, C.; Chandiran, A. K.; Nazeeruddin, M. K.; Diau, E. W.-G.; Yeh, C.-Y.; Zakeeruddin, S. M.; Grätzel, M. Porphyrin-Sensitized Solar Cells with Cobalt (II/III)Based Redox Electrolyte Exceed 12\% Efficiency. Science 2011, 334, 629-634.

(32) Kakiage, K.; Aoyama, Y.; Yano, T.; Oya, K.; Fujisawa, J.-i.; Hanaya, M. Highly-Efficient Dye-Sensitized Solar Cells with Collaborative Sensitization by Silyl-Anchor and Carboxy-Anchor Dyes. Chem. Commun. 2015, 51, 15894-15897.

(33) Hill, J. P. Molecular Engineering Combined with Cosensitization Leads to Record Photovoltaic Efficiency for Non-ruthenium Solar Cells. Angew. Chem., Int. Ed. 2016, 55, 2976-2978.

(34) Feldt, S. M.; Gibson, E. A.; Gabrielsson, E.; Sun, L.; Boschloo, G.; Hagfeldt, A. Design of Organic Dyes and Cobalt Polypyridine Redox Mediators for High-Efficiency Dye-Sensitized Solar Cells. J. Am. Chem. Soc. 2010, 132, 16714-16724.

(35) Hao, Y.; Gabrielsson, E.; Lohse, P. W.; Yang, W.; Johansson, E. M. J.; Hagfeldt, A.; Sun, L.; Boschloo, G. Peripheral Hole Acceptor Moieties on an Organic Dye Improve Dye-Sensitized Solar Cell Performance. Advanced Science 2015, 2, 1500174.

(36) Hagfeldt, A.; Boschloo, G.; Sun, L.; Kloo, L.; Pettersson, H. Dye-Sensitized Solar Cells. Chem. Rev. 2010, 110, 6595-6663.

(37) Boschloo, G.; Häggman, L.; Hagfeldt, A. Quantification of the Effect of 4-tert-Butylpyridine Addition to $\mathrm{I}^{-} / \mathrm{I}_{3}{ }^{-}$Redox Electrolytes in Dye-Sensitized Nanostructured $\mathrm{TiO}_{2}$ Solar Cells. J. Phys. Chem. B 2006, 110, 13144-13150.

(38) Pavlishchuk, V. V.; Addison, A. W. Conversion Constants for Redox Potentials Measured versus Different Reference Electrodes in aAetonitrile Solutions at $25^{\circ} \mathrm{C}$. Inorg. Chim. Acta 2000, 298, 97-102.

(39) Yang, W.; Vlachopoulos, N.; Hao, Y.; Hagfeldt, A.; Boschloo, G. Efficient Dye regeneration at low driving force achieved in triphenylamine dye LEG4 and TEMPO redox Mediator based DyeSensitized Solar Cells. Phys. Chem. Chem. Phys. 2015, 17, 1586815875 .

(40) Boschloo, G.; Hagfeldt, A. Photoinduced Absorption Spectroscopy as a Tool in the Study of Dye-Sensitized Solar Cells. Inorg. Chim. Acta 2008, 361, 729-734.

(41) Feldt, S. M.; Wang, G.; Boschloo, G.; Hagfeldt, A. Effects of Driving Forces for Recombination and Regeneration on the Photovoltaic Performance of Dye-Sensitized Solar Cells using Cobalt Polypyridine Redox Couples. J. Phys. Chem. C 2011, 115, 2150021507.

(42) Zaban, A.; Greenshtein, M.; Bisquert, J. Determination of the Electron Lifetime in Nanocrystalline Dye Solar Cells by Open-Circuit Voltage Decay Measurements. ChemPhysChem 2003, 4, 859-864. 